\title{
Nanoparticle-laden tubeless and open siphons $\dagger$
}

\author{
By J. W A NG, R. BAI AND D. D. JOSEPH \\ Department of Aerospace Engineering and Mechanics, University of Minnesota, Minneapolis, \\ MN 55455, USA
}

(Received 15 January 2004 and in revised form 9 June 2004)

Tubeless and open siphons operate without conduits, in the open, supported only by extensional stresses. Here, we demonstrate that the addition of silica nanoparticles in modest concentrations (on the order of $1 \%$ by weight) to an aqueous Poly(ethylene oxide) (PEO) solution of a moderately low concentration $(0.5 \%$ by weight $)$ has a dramatic effect on the power of the siphon as well as on the ability of the siphon to completely clean substrates. These enhanced effects may have a partly fluid mechanical explanation, since they also occur when the siphon is laden with inert sub-millimetre particles (Wang \& Joseph, J. Fluid Mech. vol. 480, 2003, p. 119). The extensional properties of PEO solutions are greatly enhanced when they are loaded with silica nanoparticles. The degradation of the PEO solution is suppressed by the addition of silica nanoparticles.

\section{Introduction}

The tubeless siphon (figure $1 a$ ) is one of the wonders of the dynamics of polymeric liquids; it is not observed in Newtonian fluids. Pictures of the tubeless siphon appear in nearly all of the recent books on the dynamics of polymeric liquids, but the siphon is not understood. Bird, Armstrong \& Hassager (1977, p. 74) remark that "... it is believed that it is the orientation and elongation of polymer molecules along the streamline that are responsible for the large axial stresses that make the siphon work". Despite the prominence given to the tubeless siphon as an example of non-Newtonian behaviour, coherent explanations of the mechanical and rheological fundamentals which make the siphon work are lacking.

The liquid column of ordinary siphons usually breaks because air enters the siphon tube. If the lowest pressure in the system at the top of the siphon falls below the vapour pressure, the siphon column will break; usually air enters before cavitation occurs. The action of the open siphon (figure $1 b$ ) depends upon the influence of gravity and upon the cohesive forces of polymeric liquids which prevent the siphon column from breaking. The difference between the tubeless siphon and the open siphon is analogous to the difference in vertical tubes between motion driven by pressure gradients and motion driven by body forces.

Recent experiments of Wang \& Joseph (2003) have shown that the addition of sub-millimetre solid particles in modest concentrations $(<10 \%$ by volume) to polymeric solutions can greatly enhance the pulling power or extensional viscosity of the suspension. Tentative explanations for the particle-laden tubeless siphon were proposed based on the characteristics of the entrance flow and particle chaining in 


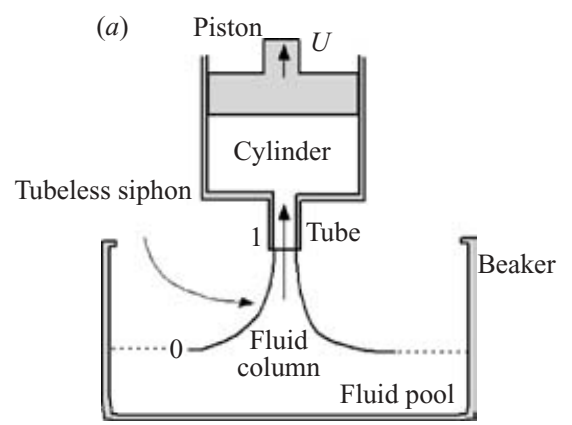

(b)

FIgURE 1. (a) Tubeless siphon: a fluid is sucked through a nozzle elevated above the surface of the fluid. Instead of the fluid breaking as for a Newtonian fluid, an unsupported fluid column is drawn from the pool below into the nozzle without breaking. $(b)$ The open-siphon effect of a $0.75 \%$ aqueous solution of PEO. Only the slightest spilling will partially empty the beaker. (From Boger \& Walters 1993.)

viscoelastic fluids. Air is prevented from entering the tube in the tubeless siphon because the polymeric liquid swells due to normal stresses as it enters the tube; this is the opposite of the well-known phenomenon of die swell in extrusion. When the polymeric liquid is laden with particles, the particles are brought up by the siphon but trapped in the eddies near the nozzle generated by the viscoelastic entrance flow; almost none of the particles enter the tube. As a result, more and more particles accumulate near the nozzle and may form a cluster around the nozzle, which prevents the air entering the tube and improves the siphon.

We change the particle size from sub-millimetre to nanometre in this study. Tubeless and open siphon experiments using an aqueous PEO solution of a moderately low concentration $(0.5 \mathrm{wt} \%)$ laden with silica nanoparticles in modest concentrations (on the order of $1 \mathrm{wt} \%$ ) show that the life and the pulling power of the siphons are significantly increased.

It is well known that the affinity between PEO molecules and silica particles is high The adsorption of PEO onto silica has been extensively studied (Howard \& McConnell 1967; Killmann et al. 1985; Killmann, Maier \& Baker 1988; Killmann \& Sapuntzjis 1994; Zaman, Bjelopavlic \& Moudgil 2000). It is believed that the adsorption mechanism between PEO molecules and silica particles is through hydrogen bonding between the ether oxygen of PEO molecules and isolated silanol groups on the silica surface (the silanol group density on silica particles is $\sim 4-5 \mathrm{SiOH} \mathrm{nm}^{-2}$ ) (Rubio \& Kitchener 1976).

We have not found any literature on nanoparticle enhancement of extensional stresses in polymer solutions, but studies of the effects of micron-sized or nanosized particles on shear properties of polymer solutions have appeared. Zaman et al. (1996, 2000) treated the effects of absorbed PEO on the rheology of colloidal silica suspensions of particles on the order of $1 \mu \mathrm{m}$ in concentrations up to $60 \%$ by volume. Their rheological studies focused on the shear viscosity. Liu, Lafuma \& Audeber (1994) studied the rheological behaviour of nanometric silica beads in relation to the adsorbed amount of high-molecular-weight PEO. They observed different rheological behaviour such as shear-induced gelation, thixotropic shear thinning and Newtonian behaviour depending on the adsorption level, number of particles per macromolecular chain, and free-polymer equilibrium concentration.

Zhang \& Archer (2002) studied linear viscoelastic properties of PEO/silica nanocomposites. They measured the elastic and loss modulus of the nanocomposite melts 
and found a transition to a solid-like response at low oscillation frequencies for particle volume fraction $\phi$ as low as $2 \%$, which is dramatically lower than the theoretical percolation threshold $(\phi \sim 30 \%)$ for solid-like behaviour in conventional particlefilled polymers. They suggested a filler networking mechanism, wherein nanosized silica particles surrounded by an immobilized shell of PEO are bridged by much larger polymer molecules, to explain their observations.

The mechanism of nanoparticles bridged by polymer molecules has been studied extensively by Otsubo and co-workers. Studies of the shear viscosity and stress relaxation behaviour of silica nanoparticle suspensions in polyacrylamide (PAAm) solutions indicated elastic behaviour at low frequencies when both the particle and polymer concentration is increased beyond certain critical levels (Otsubo \& Watanabe 1987; Otsubo 1990; Otsubo \& Nakane 1991). Flocculation of silica particles by polymer bridging was proposed to explain the observations and the boundary of the elastic behaviour was investigated using percolation theory (Otsubo 1990; Otsubo \& Nakane 1991). Shear-viscosity behaviour, normal stress and dynamic viscoelasticity were measured for copolymer nanoparticle suspensions flocculated by polymer bridging (Otsubo 1992, 1993, 1994a). It is believed that the polymer coil, whose size is comparable to the particle diameter, makes a flexible bridge between two particles. The reversibility of the bridge between the nanoparticle and polymer molecules was discussed based on the affinity between them (Otsubo 1994b, 1995, 1998, 1999).

The action of tubeless and open siphons reported here is related to the extensional properties of nanoparticle suspensions and has not been studied before. Our $\mathrm{PEO} /$ silica samples can be described as solutions of modest concentrations of macromolecules in water. The macro-molecule is created by a bridging mechanism in which silica nanoparticles are encapsulated by PEO molecules through chemical bonding; this is like beads and springs where the silica particles are the beads. We obtain a solution which possesses a great resistance to extension and a long relaxation time for the extensional stress.

\section{Sample preparation}

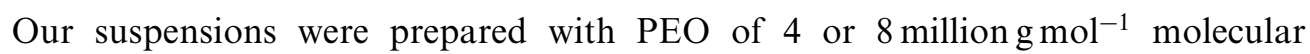
weight manufactured by Polysciences Inc., and silica nanoparticles in the form of $40.5 \mathrm{wt} \%$ water-based colloidal suspensions supplied by Nissan Chemical Industries, Ltd. Two sizes of the silica nanoparticles were used, $10-20 \mathrm{~nm}$ and $45-60 \mathrm{~nm}$. The specific surface area of the $10-20 \mathrm{~nm}$ particles is estimated to be about $200 \mathrm{~m}^{2} \mathrm{~g}^{-1}$. The suspension specific gravity $\left(20^{\circ} \mathrm{C}\right)$ is 1.3 for both sizes.

The preparation protocol was as follows. First, homogeneous aqueous PEO solutions were prepared by continuous mixing for as long as a week. Then a certain amount of nanoparticle suspension and additional water were added to the PEO solution to obtain desired PEO and silica concentrations. The samples were put into an ultrasonic bath where they were sonicated for $20 \mathrm{~min}$, followed by vigorous stirring. The sonication/stirring procedure was repeated up to four times. This is necessary to break silica agglomerates and to ensure a homogeneous suspension. The samples were left to rest for at least $24 \mathrm{~h}$ before use. Chain scission may happen in the process which adds uncertainty to the final molecular weight.

The PEO/silica suspensions have very strong viscoelastic properties. Rod-climbing and recoverable strain were evident in the process of stirring. Both the shear and extensional viscosities depend strongly on the history. 

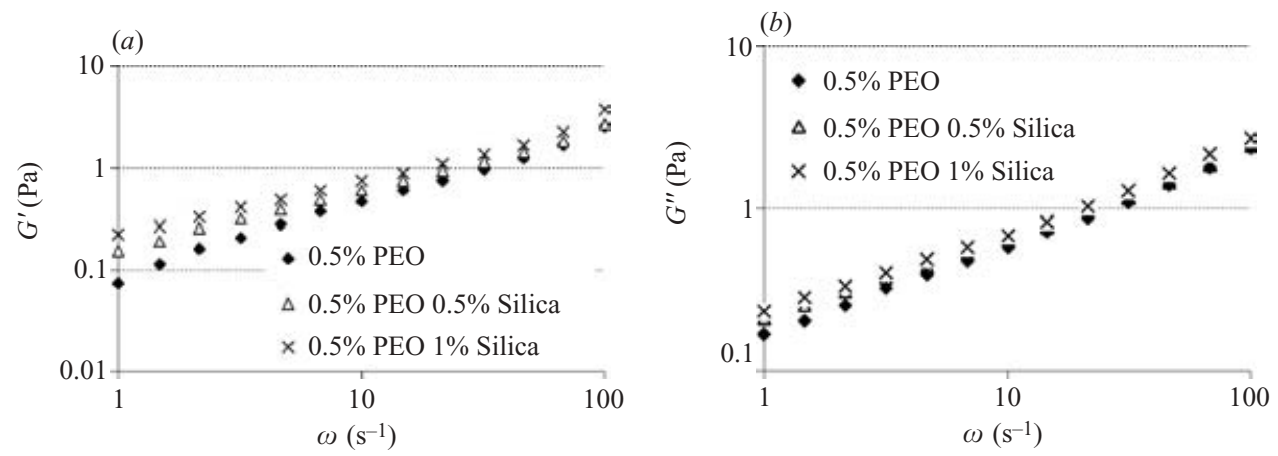

FIGURE 2. Linear viscoelastic properties of the PEO/silica suspensions as a function of the frequency. Measurements were carried out at room temperature. The molecular weight of PEO was 4 million $\mathrm{g} \mathrm{mol}^{-1}$ and the size of the silica particles was $10-20 \mathrm{~nm}$ in these samples. (a) Elastic modulus $G^{\prime} ;(b)$ Loss modulus $G^{\prime \prime}$. There is no evidence of a plateau modulus.

\section{Rheological properties}

Linear viscoelastic properties and shear viscosities of the PEO/silica suspensions were measured using a Rheometric Scientific ARES rheometer with parallel plates of $50 \mathrm{~mm}$ diameter. Figure 2 shows that the values of the elastic modulus $G^{\prime}$ and loss modulus $G^{\prime \prime}$ increase moderately as the concentration of the nanoparticles increases from zero to $1 \%$. Our results are consistent with Zhang \& Archer (2002) who reported that $G^{\prime}$ and $G^{\prime \prime}$ of $\mathrm{PEO} /$ silica nanocomposites increased with the particle loading. Their data showed that at low frequencies (on the order of $0.01 \mathrm{~s}^{-1}$ ), the values of $G^{\prime}$ and $G^{\prime \prime}$ increased dramatically $\left(10^{3}-10^{4}\right.$ times) when the volume fraction of the nanoparticles increased from zero to $4 \%$. They reported that $G^{\prime}$ was almost constant at low frequencies when the particle volume fraction was higher than $2 \%$. We were not able to measure $G^{\prime}$ and $G^{\prime \prime}$ of our samples at such low frequencies due to the limit of the rheometer. Their data also showed that the effect of particle loading on $G^{\prime}$ and $G^{\prime \prime}$ was relatively weak at high frequencies (on the order of $100 \mathrm{~s}^{-1}$ ). This is close to the range of the frequencies we measured and their conclusion is compatible with our observation.

Figure 3 shows that the shear viscosities of the PEO/silica suspensions increase with the nanoparticle concentration. Similar results were obtained by Zaman et al. (2000) for silica particles on the order of $1 \mu \mathrm{m}$.

\section{Tubeless siphon experiments}

The experimental setup for the tubeless siphon is shown in figure 1(a). The addition of silica nanoparticles to PEO solutions significantly improves the power of the siphon. For example, we may compare the tubeless siphon of a $0.5 \% 4$ million $\mathrm{g} \mathrm{mol}^{-1} \mathrm{PEO}$ solution with and without nanoparticles; the other conditions such as the initial volume and the piston speed $U$ are the same in the two cases. Without nanoparticles, there is a puddle of liquid left in the beaker after the siphon action; with $2.34 \%$ silica nanoparticles, the siphon has a much thicker fluid column, lasts longer, and a complete cleaning is achieved. The movies of the tubeless siphon experiments are available at http://www.aem.umn.edu/research/particles/nano/.

An emptying fraction $F$ can be defined as the ratio of the volume emptied from the beaker to the initial volume of the suspension. We show $F$ as a function of the piston speed $U$ for several $\mathrm{PEO} /$ silica suspensions in table 1 . The addition of only 


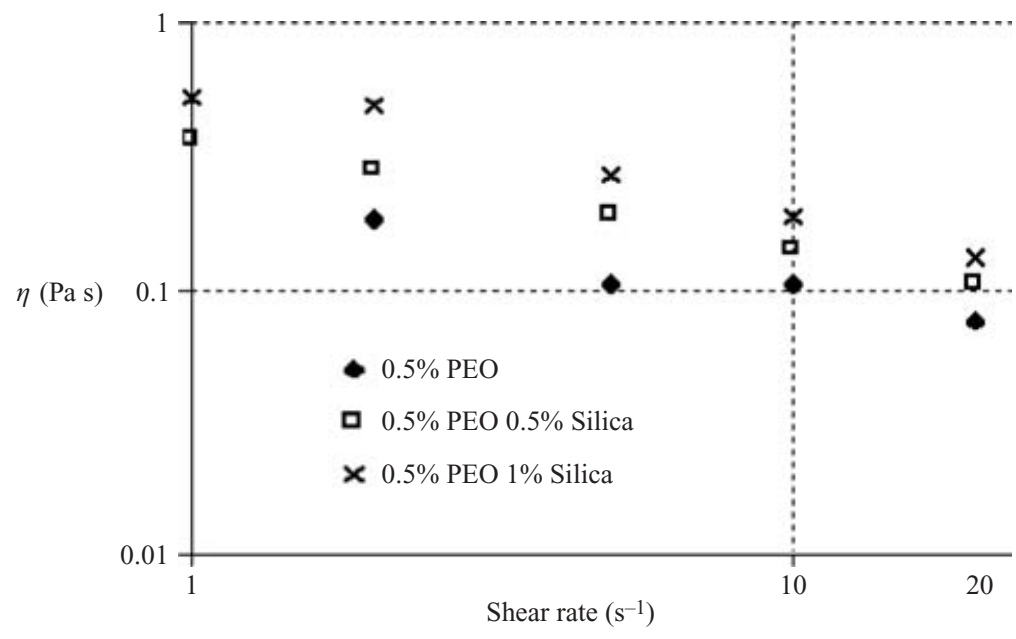

FIGURE 3. Shear viscosity of the PEO/silica suspensions as a function of the shear rate. The molecular weight of PEO was 4 million $\mathrm{g} \mathrm{mol}^{-1}$ and the size of the silica particles was $10-20 \mathrm{~nm}$ in these samples.

\begin{tabular}{cccc} 
PEO (wt \%) & Silica (wt \%) & $U\left(\mathrm{~cm} \mathrm{~s}^{-1}\right)$ & $F(\%)$ \\
0.5 & 0 & 0.070 & 35 \\
& & 0.128 & 82 \\
& & 0.185 & 88 \\
0.5 & \multirow{2}{*}{1.18} & 0.243 & 93 \\
& & 0.070 & 99 \\
& & 0.128 & 100 \\
0.5 & 2.34 & 0.185 & 100 \\
0.5 & 4.74 & 0.243 & 100 \\
& & 0.070 & 100 \\
& & 0.070 & 100
\end{tabular}

TABLE 1. The emptying fraction $F$ as a function of the piston speed $U$ using $\mathrm{PEO} /$ silica suspensions. The molecular weight of the PEO is 4 million $\mathrm{g} \mathrm{mol}^{-1}$ and the size of the silica particles is $10-20 \mathrm{~nm}$ in these samples.

$1.18 \%$ silica nanoparticles can improve the emptying fraction $F$ from $35 \%$ to almost $100 \%$ at a low piston speed $\left(U=0.070 \mathrm{~cm} \mathrm{~s}^{-1}\right)$. At higher silica concentrations, the suspension can be completely cleaned up, leaving a virtually dry beaker. Significant swelling in the liquid column was observed during the siphon action, indicating strong normal stresses. In the range of the concentrations we studied (up to $4.74 \%$ ), the pulling power of the suspension increases with the nanoparticle concentration.

The improvement of the siphon by addition of nanoparticles is attributed to the bridging mechanism. The adsorption of PEO on silica can be considered irreversible due to the strong affinity between them. A high-molecular-weight polymer can adsorb onto more than two nanoparticles (Otsubo 1992). Nanoparticles are therefore connected by polymer molecules even when they are quite far apart in comparison with their size. Thus, even a relatively small concentration of nanoparticles can cause significant change in solution properties (Zhang \& Archer 2002). Relative 


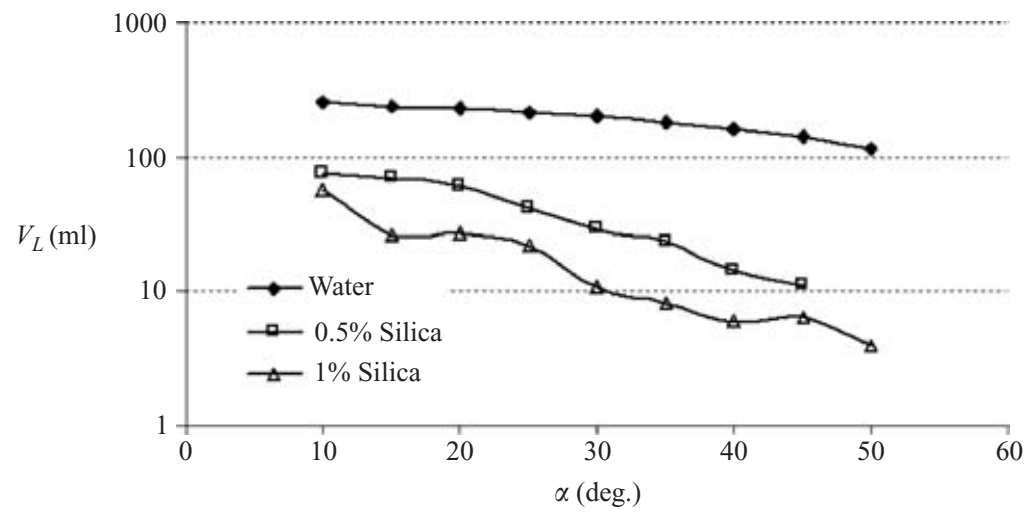

Figure 4. The volume $V_{L}$ left in the beaker as a function of the tilting angle $\alpha$. The three curves are for water, PEO solutions laden with $0.5 \%$ and $1 \% 45-60 \mathrm{~nm}$ silica particles. The molecular weight of PEO is 4 million $\mathrm{g} \mathrm{mol}^{-1}$ and the concentration of PEO is $0.5 \%$.

motion between polymer chains is retarded by immobilization of polymers attached to nanoparticle surfaces and polymer confinement between nanoparticles (Zhang \& Archer 2002). This mechanism provides strong cohesive forces to support the siphon column, enabling the siphon to pull out more liquid.

\section{Open siphon experiments}

In the open siphon experiment, the beaker holding the testing fluid is tilted at an angle $\alpha$ so that a portion of the fluid spills out of the beaker. If the fluid is Newtonian, the flow stops when the fluid surface levels with the edge. For viscoelastic fluids, the flow can continue to empty the beaker partially or even completely. The movies of the open siphon experiments can be viewed at http://www.aem.umn.edu/research/ particles/opensiphon/.

\subsection{Effects of the tilting angle}

The strength of the open siphon is affected by the tilting angle $\alpha$. For a Newtonian fluid, the volume $V_{L}$ of the fluid left in the beaker after the breakdown the siphon action can be easily computed. If we assume that before the siphon the beaker is full of fluid, then a simple geometric derivation would show

$$
V_{L}=V_{0}-\pi a^{3} \tan (\alpha)
$$

where $V_{0}$ is the original volume of the fluid, and $a$ is the radius of the beaker (assuming that the beaker can be approximated by a cylinder). Obviously the volume left in the beaker decreases as the tilting angle increases.

We carried out open siphon experiments with tilting angles from $10^{\circ}$ to $50^{\circ}$ using $0.5 \%$ aqueous PEO solutions laden with silica nanoparticles. In all the experiments, the original volume $V_{0}$ is $271 \mathrm{ml}$. The volume left $V_{L}$ is plotted against the tilting angle $\alpha$ in figure 4. The experimental data using water, which follows equation (5.1), is also plotted in figure 4 for the purpose of comparison. Figure 4 shows that as $\alpha$ increases, $V_{L}$ decreases faster for $\mathrm{PEO} /$ silica suspensions than for water.

\subsection{Effects of the height of the siphon column}

In open siphon experiments, the flow is driven by the gravity of the siphon column. The longer the siphon column, the more liquid flows out of the beaker. We control 


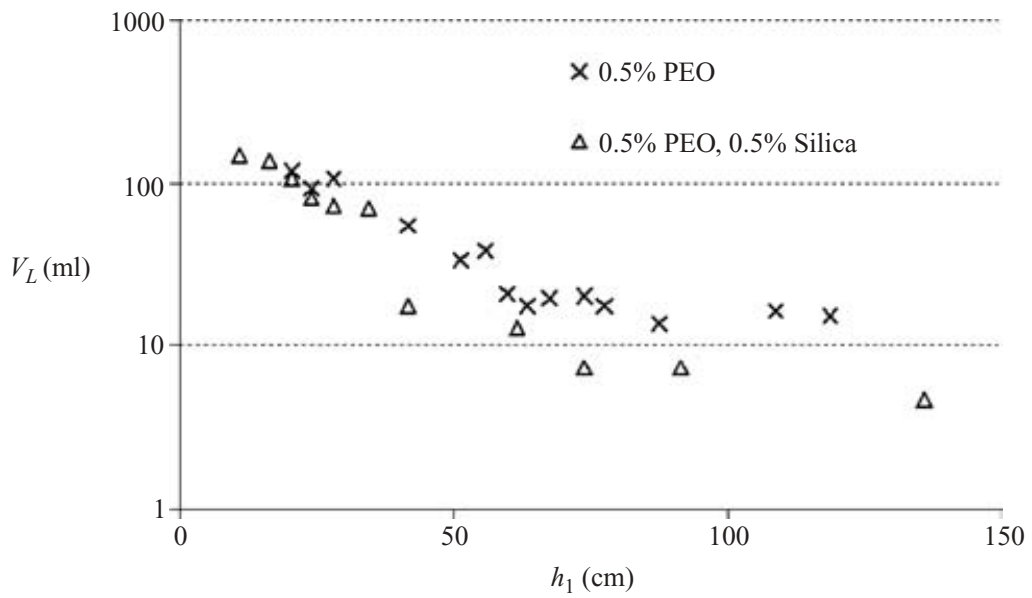

Figure 5. The volume $V_{L}$ left in the beaker as a function of $h_{1}$, the initial height of the siphon column, for a $0.5 \% 8$ million $\mathrm{g} \mathrm{mol}^{-1} \mathrm{PEO}$ solution, and the same solution but laden with $0.5 \%$ $45-60 \mathrm{~nm}$ silica particles. The tilting angle in these experiments is fixed at $15^{\circ}$.

the height of the siphon column by adjusting the distance from the tip of the beaker to the lower liquid reservoir. It should be noted that the height is changing as more liquid flows into the lower reservoir; we did not account for this change and the values reported here are the initial heights of the siphon column, indicated by the symbol $h_{1}$. We plot the volume $V_{L}$ left in the beaker as a function of $h_{1}$ in figure 5 . The two curves are for a $0.5 \% 8$ million $\mathrm{g} \mathrm{mol}^{-1}$ PEO solution, and the same solution but laden with $0.5 \% 45-60 \mathrm{~nm}$ silica particles. The tilting angle in these experiments is fixed at $15^{\circ}$. As the height of the fluid column increases, $V_{L}$ decreases and tends to zero.

\subsection{Effects of the nanoparticles}

We carried out open siphon experiments with the tilting angle fixed at $15^{\circ}$ and the initial height of the siphon column $h_{1}$ fixed at $42.3 \mathrm{~cm}$. In all the experiments, the beaker was full of fluid before the siphon, $V_{0}=271 \mathrm{ml}$. Let $V_{1}$ stand for the volume of a Newtonian fluid left in the beaker after the flow stops; $V_{1}=240 \mathrm{ml}$ in our experiments. We define the emptying fraction $F$ as

$$
F=\frac{V_{1}-V_{L}}{V_{1}} \times 100 \% .
$$

The reason for using $V_{1}$ instead of $V_{0}$ to define $F$ is that the portion of the fluid $\left(V_{0}-V_{1}\right)$ flows out of the beaker simply due to gravity and should not be used to characterize the viscoelasticity of the testing fluid. Under the definition (5.2), $F=0$ for a Newtonian fluid and $F=100 \%$ when a complete cleaning is achieved. The measured values of the emptying fraction are listed in table 2 and plotted in figure 6 . For each $\mathrm{PEO} /$ silica suspension, we performed the experiments three to four times and the averaged values of $F$ are reported here.

The data in table 2 and figure 6 show that the addition of silica particles $(10-20 \mathrm{~nm}$ or $45-60 \mathrm{~nm}$ ) to 4 million $\mathrm{g} \mathrm{mol}^{-1}$ PEO solutions increases the emptying fraction

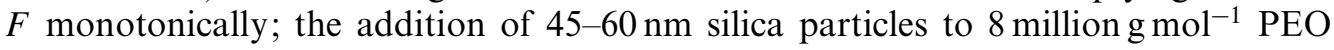
solutions also increases $F$ monotonically; but the addition of $10-20 \mathrm{~nm}$ silica particles to 8 million $\mathrm{g} \mathrm{mol}^{-1} \mathrm{PEO}$ solutions first decreases $F$ then increases $F$. The most 


\begin{tabular}{|c|c|c|c|c|}
\hline PEO MW $\left(\mathrm{g} \mathrm{mol}^{-1}\right)$ & PEO (wt \%) & Silica (wt \%) & Silica size $(\mathrm{nm})$ & $F(\%)$ \\
\hline \multirow[t]{3}{*}{8 million } & 0.5 & 0 & - & 77.1 \\
\hline & & $\begin{array}{l}0.5 \\
1.0 \\
2.0\end{array}$ & $10-20$ & $\begin{array}{l}20.8 \\
62.5 \\
87.5\end{array}$ \\
\hline & & $\begin{array}{l}0.5 \\
1.0 \\
2.0\end{array}$ & $45-60$ & $\begin{array}{l}92.5 \\
98.3 \\
99.1\end{array}$ \\
\hline \multirow[t]{3}{*}{4 million } & 0.5 & 0 & - & 50.5 \\
\hline & & $\begin{array}{l}0.5 \\
1\end{array}$ & $10-20$ & $\begin{array}{l}88.0 \\
94.2\end{array}$ \\
\hline & & $\begin{array}{l}0.25 \\
0.5 \\
0.75 \\
1.0 \\
1.25\end{array}$ & $45-60$ & $\begin{array}{l}58.3 \\
70.6 \\
81.5 \\
89.1 \\
89.5\end{array}$ \\
\hline
\end{tabular}

TABLE 2. Measurements of the emptying fraction $F$ in the open siphon experiments of $\mathrm{PEO} /$ silica suspensions. The tilting angle in these experiments is $15^{\circ}$ and the initial height of the siphon column $h_{1}$ is $42.3 \mathrm{~cm}$.

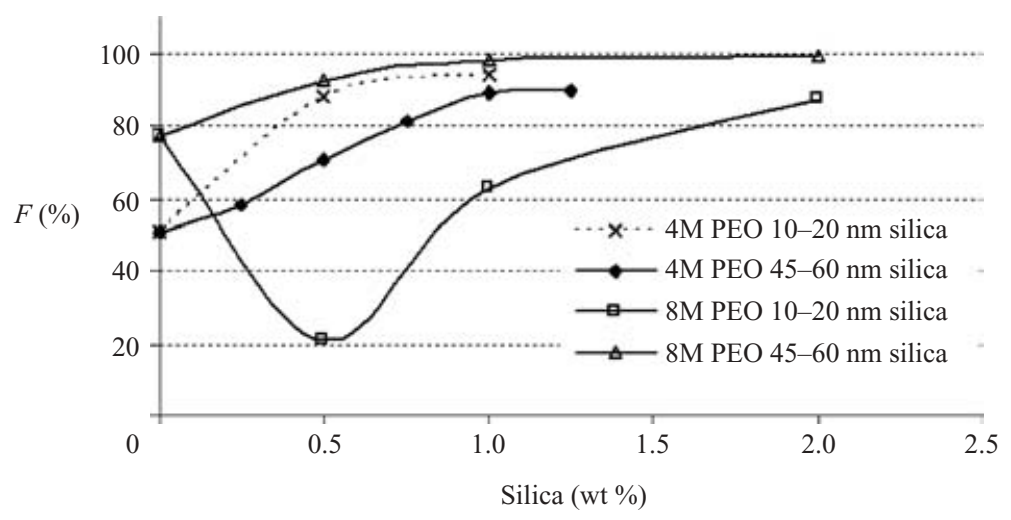

FiguRE 6. Effects of the silica nanoparticle concentration in PEO solutions on the emptying fraction $F$. The data are from table 2 .

dramatic effect was generated by the addition of $1 \%$ or $2 \% 45-60 \mathrm{~nm}$ silica particles to 8 million $\mathrm{g} \mathrm{mol}^{-1}$ PEO solutions, which leads to an almost complete cleanup.

To understand these results, it is necessary to point out that a high ratio of extensional viscosity to shear viscosity is necessary for large values of $F$ in open siphons. We have presented part of the shear viscosity data in $\S 3$. In the Appendix by Michael Owens, apparent extensional viscosities and relaxation times $\lambda$ measured in capillary thinning experiments are presented. The relaxation time $\lambda$ characterizes the extensional property of the suspension; the larger $\lambda$, the stronger the resistance to extensional deformation.

The values of $\lambda$ and shear viscosity $\eta$ at a shear rate of $2 \mathrm{~s}^{-1}$ are given in table 5 in the Appendix. The data show that the resistance to extensional and shear deformations increases with the nanoparticle concentration in 4 million $\mathrm{g} \mathrm{mol}^{-1}$ PEO solutions. Moreover, the increase of the resistance to extensional deformation is generally more 


\begin{tabular}{cccccc}
\hline Particle size & $10-20 \mathrm{~nm}$ & $45-60 \mathrm{~nm}$ & $212-300 \mu \mathrm{m}$ & $300-425 \mu \mathrm{m}$ & $600-710 \mu \mathrm{m}$ \\
$F(\%)$ & 20.8 & 92.5 & 89.6 & 89.6 & 90.9
\end{tabular}

TABLE 3. Effects on the emptying fraction $F$ in open siphon experiments of particles of different sizes. The fluids are 8 million $\mathrm{g} \mathrm{mol}^{-1} 0.5 \%$ PEO solutions laden with $0.5 \%$ particles. The tilting angle in these experiments is $15^{\circ}$ and the initial height of the siphon column $h_{1}$ is $42.3 \mathrm{~cm}$.

significant than to shear deformation. For example, when 1\% 10-20 nm particles are added to a 4 million $\mathrm{g} \mathrm{mol}^{-1}$ PEO solution, $\lambda$ increases by $1250 \%$ whereas $\eta$ increases only by $167 \%$. These results agree well with the observation that $F$ increases with the particle concentration in 4 million $\mathrm{g} \mathrm{mol}^{-1}$ PEO solutions. The same argument can be applied to 8 million $\mathrm{g} \mathrm{mol}^{-1}$ PEO solutions laden with $45-60 \mathrm{~nm}$ particles. However, in 8 million $\mathrm{g} \mathrm{mol}^{-1}$ PEO solutions laden with $10-20 \mathrm{~nm}$ particles, the increase of the shear viscosity is much more significant. The value of $\eta$ at $0.5 \%$ particle concentration is 7.2 times that of the clean PEO solution, and 1.4 times that at $1 \%$ particle concentration. These data help to understand the reason why $F$ at $0.5 \%$ particle concentration is the lowest point on the curve in figure 6 .

The values of $\lambda$ and $\eta$ cannot be strictly correlated to $F$. In table 5, the largest value of $F$ does not correspond to the largest value of $\lambda$ or the smallest value of $\eta$. The capillary thinning flow is highly transient and the relaxation time $\lambda$ depends on the constitutive equation used. On the other hand, the open siphon is also a transient flow and the shear and extensional rates are changing constantly. The quantitative relation between the shear and extensional viscosities and the emptying fraction is not known and definitely not simple. Nonetheless, the measurements of $\lambda$ and $\eta$ help to understand the open siphon experiments qualitatively.

\subsection{Effects of the particle size}

We investigate the effects on the open siphon of particles of different sizes, ranging from 10-20 nm to sub-millimetre. Besides the two sizes of silica nanoparticles, styrene divinylbenzene copolymer particles of three sizes, $212-300 \mu \mathrm{m}, 300-425 \mu \mathrm{m}$, and 600 $710 \mu \mathrm{m}$, were also used in the open siphon experiments. The copolymer particles were purchased from the Dow Chemical Company and the density of them was slightly larger than that of the PEO solution. The PEO/copolymer suspensions were wellmixed before the experiments and no sensible sedimentation was observed during the experiments. For each particle size, we prepared an 8 million $\mathrm{g} \mathrm{mol}^{-1} 0.5 \%$ PEO solution laden with $0.5 \%$ particles. The values of the emptying fraction $F$ using these suspensions are listed in table 3.

Table 3 shows that the three copolymer particle suspensions have higher values of $F$ than $F=77.1 \%$ for the clean PEO solution. Therefore the addition of inert submillimetre particles to PEO solutions can increase the emptying fraction of an open siphon; a similar effect was observed in the tubeless siphon (Wang \& Joseph 2003). Evidently, this effect is not sensitive to the particle size, for particles ranging from 200-700 $\mu \mathrm{m}$ give almost the same value of $F$. The mechanism for the improvement of the extensional properties of polymer solutions by sub-millimetre particles may not be the same as by nanoparticles and is not clearly understood. But it can be shown by analysis (Joseph \& Feng 1996, Wang \& Joseph 2004) that the stress on a particle due to viscoelasticity is opposite to that due to the inertia; the normal stress on the particle can change from compression to tension. This tension may help to hold the polymer chains and particles together, leading to a higher extensional viscosity. 


\begin{tabular}{lccccc}
\hline $\begin{array}{c}\text { PEO MW } \\
\left(\mathrm{g} \mathrm{mol}^{-1}\right)\end{array}$ & $\begin{array}{c}\text { Silica } \\
(\text { wt } \%)\end{array}$ & $\begin{array}{c}\text { Silica } \\
\text { size }(\mathrm{nm})\end{array}$ & $\begin{array}{c}F(\%) \text { (fresh } \\
\text { suspension) }\end{array}$ & $\begin{array}{c}F(\%) \text { (aged } \\
\text { suspension) }\end{array}$ & $\begin{array}{c}\text { Aging time } \\
\text { (days) }\end{array}$ \\
8 million & 0.5 & $10-20$ & 20.8 & 1 & 60 \\
& 1.0 & & 62.5 & 60.4 & 60 \\
& 2.0 & & 87.5 & 73.0 & 60 \\
& 0.5 & $45-60$ & 92.5 & 89.5 & 30 \\
& 1.0 & & 98.3 & 98.2 & 30 \\
4 million & 2.0 & & 99.1 & 99.1 & 60 \\
& 0.5 & $45-60$ & 70.6 & 22.9 & 50 \\
& 1.0 & & 89.1 & 47.9 & 45
\end{tabular}

TABLE 4. A comparison of the emptying fraction $F$ using fresh PEO/silica suspensions with using the same suspensions left at the room temperature and exposed to light for a period of time. The tilting angle in these experiments is $15^{\circ}$ and the initial height of the siphon column $h_{1}$ is $42.3 \mathrm{~cm}$. The PEO concentration in these samples is $0.5 \%$.

In table 3, the largest $F$ occurs when the particle size is $45-60 \mathrm{~nm}$. There is possibly an optimal particle size for which the emptying fraction in an open siphon is the maximum. Nanometer to sub-millimetre is a wide range of size; our sampling is far from complete and we are not in a position to predict what the optimal size could be.

\subsection{Effects of degradation}

It is well known that PEO can be easily degraded by oxidative attack, and this degradation can be accelerated in the presence of heavy metal ions, oxidizing agents, strong acids, and radiation (McGary 1960; Duval \& Sarazin 2003). If a bottle of PEO solution is left at room temperature and exposed to light for over a month, it will become almost Newtonian. We noticed that the presence of silica nanoparticles seemed to slow down the degradation of PEO. In table 4, we compare the emptying fraction $F$ in open siphon experiments using fresh $\mathrm{PEO} /$ silica suspensions with using aged suspensions.

From table 4 , one can see that suspensions with only $0.5 \%$ silica particles show severe degradation, whereas the degradation of suspensions with $1 \%$ or $2 \%$ silica particles is much less severe. In particular, the 8 million $\mathrm{g} \mathrm{mol}^{-1} \mathrm{PEO}$ solution laden with $1 \%$ or $2 \% 45-60 \mathrm{~nm}$ silica particles shows almost no degradation, as measured in the open siphon experiments. The reason for this effect is not clear; apparently PEO molecules bonded with silica particles are less liable to oxidative attack.

\section{Conclusion}

Experiments on tubeless and open siphons of PEO/silica nanoparticle suspensions show that small concentrations of nanoparticles in polymer solutions can dramatically change the extensional properties of the polymer solutions. An explanation based on a bridging mechanism with particles encapsulated by polymer molecules is proposed. The addition of particles with size ranging from nanometre to sub-millimetre could increase the emptying fraction in open siphon experiments; there is possibly an optimal particle size for which the emptying fraction is maximum.

The presence of silica nanoparticles seems to slow down the degradation of PEO solutions. The degradation of suspensions with $1 \%$ or $2 \%$ silica particles is much 
less severe than that of clean PEO solutions or suspensions with only $0.5 \%$ silica particles.

Linear viscoelastic properties and shear viscosities of the PEO/silica suspensions were also measured. Data show that the values of the elastic modulus $G^{\prime}$, loss modulus $G^{\prime \prime}$ and the shear viscosity all increase moderately as the concentration of the nanoparticles increases. The apparent extensional viscosity and relaxation time were measured in capillary thinning experiments. The data reveal that the addition of silica nanoparticles significantly increases the resistance to extensional deformation and the relaxation time of the polymeric solution.

The cleaning property of the tubeless siphon of nanoparticle suspensions may find applications in decontamination and cleanup. The present work is one realization of the opportunities to construct new fluid materials with special properties as a composition of nanoparticle and polymeric solutions.

This work was partially supported by an SGER grant from NSF, by an STIR grant from ARO and by the Department of Basic Energy Science at DOE.

\title{
Appendix. Capillary thinning experiments
}

\author{
By Michael S. Owens \\ Coating Process Fundamentals Program \& Microstructured Polymers, \\ Department of Chemical Engineering \& Materials Science, University of Minnesota, \\ Minneapolis, MN 55455, USA
}

The extensional properties of PEO/silica suspensions were measured in capillary thinning experiments. A capillary thinning indexer consists of a liquid drop initially placed between two vertically aligned plates. The upper plate is rapidly translated vertically to a finite displacement to create a liquid bridge. The bridge diameter at the horizontal mid-plane is measured optically, and rheological information is extracted by fitting the resulting diameter versus time data to an appropriate constitutive equation.

The theory and a review of previous literature on capillary thinning can be found in Entov \& Hinch (1997), McKinley \& Tripathi (2000) and Anna \& McKinley (2001). An Oldroyd-B liquid is predicted to thin exponentially with time:

$$
D(t)=\left(\frac{\eta_{p} D_{1}^{4}}{2 \lambda \sigma}\right)^{1 / 3} \exp \left(\frac{-t}{3 \lambda}\right)
$$

where $D$ is the bridge diameter at the horizontal mid-plane, $\lambda$ is the relaxation time, $\eta_{p}$ is the polymeric contribution to the solution viscosity, $\sigma$ is the surface tension, and $D_{1}$ is the first diameter at which the data fitting begins. Entov \& Hinch (1997) made the constitutive equation more physical by acknowledging the presence of a spectrum of relaxation times and including the finite extensibility of polymer chains. During the initial thinning process (low strain/early time) the solution behaves as a Newtonian liquid. At intermediate strains where viscous forces become negligible relative to rising elasticity, but before polymer chains reach their finite extensible limit, the Oldroyd-B behaviour is recovered. The accuracy of the Oldroyd-B relaxation time for dilutemonodisperse polystyrene solutions was investigated by Anna et al. (2001) and found to agree well with independent measurements of relaxation time in oscillatory shear and extensional flow using the filament stretching rheometer pioneered by Sridhar 


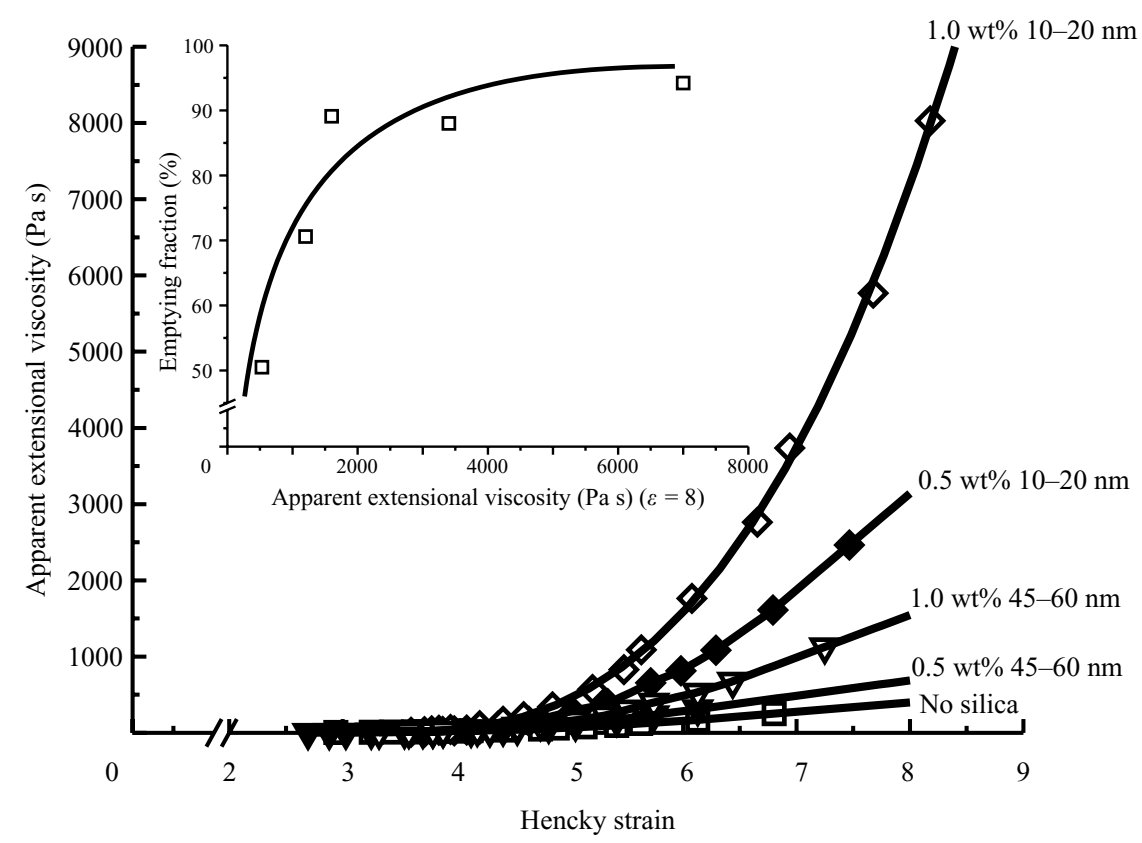

FIGURE 7. Apparent extensional viscosities versus Hencky strain from capillary thinning experiments and correlation of the extensional viscosity at a Hencky strain of eight with the emptying fraction. The molecular weight of PEO is 4 million $\mathrm{g} \mathrm{mol}^{-1}$ and the concentration of PEO is $0.5 \%$.

\begin{tabular}{cccccc}
\hline $\begin{array}{c}\text { PEO MW } \\
\left(\text { million } \mathrm{g} \mathrm{mol}^{-1}\right)\end{array}$ & $\begin{array}{c}\text { Silica concentration } \\
(\%)\end{array}$ & $\begin{array}{c}\text { Silica size } \\
(\mathrm{nm})\end{array}$ & $\begin{array}{c}\eta\left(\dot{\gamma}=2 \mathrm{~s}^{-1}\right) \\
(\mathrm{Pa} \mathrm{s})\end{array}$ & $\begin{array}{c}\lambda \\
(\mathrm{s})\end{array}$ & $\begin{array}{c}F \\
(\%)\end{array}$ \\
4 & 0 & - & 0.182 & 0.2 & 50.5 \\
4 & 0.5 & $10-20$ & 0.280 & 1.2 & 88.0 \\
4 & 1.0 & $10-20$ & 0.486 & 2.7 & 94.2 \\
4 & 0.5 & $45-60$ & 0.404 & 0.4 & 70.6 \\
4 & 1.0 & $45-60$ & 0.530 & 0.7 & 89.1 \\
8 & 0 & - & 0.479 & 0.25 & 77.1 \\
8 & 0.5 & $10-20$ & 3.45 & 3 & 20.8 \\
8 & 1 & $10-20$ & 2.43 & 2.75 & 62.5 \\
8 & 0.5 & $45-60$ & 0.469 & 0.6 & 92.5 \\
8 & 1 & $45-60$ & 0.865 & 0.7 & 98.3
\end{tabular}

TABLE 5. The values of the shear viscosity $\eta$ at a shear rate of $2 \mathrm{~s}^{-1}$, the relaxation time $\lambda$ from capillary thinning experiments, and the emptying fraction $F$ from open siphon experiments. The concentration of PEO is $0.5 \%$ in these suspensions.

et al. (1991). An apparent extensional viscosity can be calculated from (A 2):

$$
\eta_{E x t}=\frac{2 \sigma / D(t)}{-2 \frac{\mathrm{d} \ln \left(D_{0} / D(t)\right)}{\mathrm{d} t}}
$$

where $D_{0}$ is the diameter of the fluid cylinder before deformation, $2 \sigma / D(t)$ is the capillary pressure and $-2 \mathrm{~d} \ln \left(D_{0} / D(t)\right) / \mathrm{d} t$ is the extensional rate.

The relaxation time and apparent extensional viscosity are given in table 5 and figure 7, respectively. The single relaxation time for each suspension was extracted by 
fitting the single exponential-function (A 1) over the broadest range of data giving the least error; for a better fitting a spectrum of relaxation times is required. We present the values of $\lambda$ and $F$ along with the shear viscosity $\eta$ at a shear rate of $2 \mathrm{~s}^{-1}$ in table 5. Interpretation of the data can be found in $\S 5.3$.

\section{REFERENCES}

Anna, S. L. \& McKinley, G. H. 2001 Elasto-capillary thinning and breakup of model elastic liquids. J. Rheol. 45, 115-138.

Anna, S. L., McKinley, G. H., Ngyen, D. A., Sridhar, T., Muller, S. J., Huang, J. \& James, D. F. 2001 An interlaboratory comparison of measurements from filament-stretching rheometers using common test fluids. J. Rheol. 45, 83-114.

Bird, R. B., Armstrong, R. C. \& Hassager, O. 1977 Dynamics of Polymeric Liquids. Fluid Mechanics, Volume 1. Wiley.

Boger, D. V. \& Walters, K. 1993 Rheological Phenomena in Focus. Elsevier.

Duval, M. \& Sarazin, D. 2003 Properties of PEO in dilute solution under stirring. Macromolecules 36, 1318-1323.

Entov, V. M. \& Hinch, E. J. 1997 Effect of a spectrum of relaxation times on the capillary thinning of a filament of elastic liquid. J. Non-Newtonian Fluid Mech. 72, 31-53.

Howard, G. J. \& McConnell, P. 1967 Adsorption of polymers at the solution-solid interface. I. Polyethers on silica. J. Phys. Chem. 71, 2974-2980.

JoSEPH, D. D. \& Feng, J. 1996 A note on the forces that move particles in a second-order fluid. J. Non-Newtonian Fluid Mech. 64, 229-302.

Killmann, E., Maier, H. \& BaKer, J. A. 1988 Hydrodynamic layer thicknesses of various adsorbed polymers on precipitated silica and polystyrene latex. Colloids Surf. 31, 51-71.

Killmann, E., Maier, H., Kaniut, P. \& Gütling, N. 1985 Photon correlation spectrometric measurements of the hydrodynamic layer thicknesses of adsorbed polyethylene oxides on precipitated silica. Colloids Surf. 15, 261-276.

Killmann, E. \& SapuntzJis, P. 1994 Dynamic light scattering of polystyrene latex and silica with adsorbed poly(ethylene oxide) layers - influence of ionic strength and coverage. Colloids Surf. A 86, 229-238.

Liu, S. F., Lafuma, F. \& Audeber, R. 1994 Rheological behaviour of moderately concentrated silica suspensions in the presence of adsorbed poly(ethylene oxide). Colloid Polym. Sci. 272, 196-203.

McGary, C. W. JR. 1960 Degradation of Poly(ethylene Oxide). J. Polymer Sci. XLVI, 51-57.

McKinley, G. H \& Tripathi, A. 2000 How to extract the Newtonian viscosity from capillary breakup measurements in a filament rheometer. J. Rheol. 44, 653-670.

Otsuво, Y. 1990 Elastic percolation in suspensions flocculated by polymer bridging. Langmuir 6, $114-118$.

Otsubo, Y. 1992 Dilatant flow of flocculated suspensions. Langmuir 8, 2336-2340.

Otsuвo, Y. 1993 Size effects on the shear-thickening behaviour of suspensions flocculated by polymer bridging. J. Rheol. 37, 799-809.

Otsubo, Y. 1994a Normal stress behaviour of highly elastic suspensions. J. Colloid Interface Sci. 163, 507-511.

Otsuво, Y. 1994b Effect of surfactant adsorption on the polymer bridging and rheological properties of suspensions. Langmuir 10, 1018-1022.

Otsubo, Y. 1995 Rheology control of suspensions by soluble polymers. Langmuir 11, 1893-1898.

Otsuвo, Y. 1998 Effect of adsorption affinity of polymers on the viscosity behaviour of suspensions. J. Colloid Interface Sci. 204, 214-216.

Otsuвo, Y. 1999 Rheological behaviour of suspensions flocculated by weak bridging of polymer coils. J. Colloid Interface Sci. 215, 99-105.

Otsubo, Y. \& Nakane, Y. 1991 Simulation of bridging flocculation and elastic percolation in suspensions. Langmuir 7, 1118-1123.

Otsubo, Y. \& Watanabe, K. 1987 Rheological behaviour of silica suspensions flocculated by bridging. J. Non-Newtonian Fluid Mech. 24, 265-278. 
Rubio, J. \& Kitchener, J. A. 1976 The mechanism of adsorption of polyethylene oxide flocculant on silica. J. Colloid Interface Sci. 57, 132-142.

Sridhar, T., Tirtaatmadja, V., Nguyen, D. A. \& Gupta, R. K. 1991 Measurement of extensiona viscosity of polymer solutions. J. Non-Newtonian Fluid Mech. 40, 271-280.

Wang, J. \& JosePh, D. D. 2003 Particle-laden tubeless siphon. J. Fluid. Mech. 480, 119-128.

WANG, J. \& JoSEPH, D. D. 2004 Potential flow of a second-order fluid over a sphere or an ellipse. J. Fluid. Mech. 511, 201-215.

Zaman, A. A., Bjelopavlic, M. \& Moudgil, B. M. 2000 Effect of adsorbed polyethylene oxide on the rheology of colloidal silica suspensions. J. Colloid Interface Sci. 226, 290-298.

Zaman, A. A., Moudgil, B. M., Fricke, A. L. \& El-Shall, H. 1996 Rheological behaviour of highly concentrated aqueous silica suspensions in the presence of sodium nitrated and polyethylene oxide. J. Rheol. 40, 1191-1210.

ZhANG, Q. \& ARCher, L. A. 2002 Poly(ethylene oxide)/Silica nanocomposites: structure and rheology. Langmuir 18, 10435-10442. 